\title{
Lieux magiques. Magie des lieux, Mélanges offerts à Claude Foucart, études réunies et présentées par Simone Bernard-Griffiths et Angels Santa
}

\section{Philippe Andrès}

\section{(2) OpenEdition Journals \\ Édition électronique \\ URL : http://journals.openedition.org/studifrancesi/8286 \\ DOI : 10.4000/studifrancesi.8286 \\ ISSN : 2421-5856 \\ Éditeur \\ Rosenberg \& Sellier}

\section{Édition imprimée}

Date de publication : 1 mai 2009

Pagination : 184-185

ISSN : 0039-2944

\section{Référence électronique}

Philippe Andrès, «Lieux magiques. Magie des lieux, Mélanges offerts à Claude Foucart, études réunies et présentées par Simone Bernard-Griffiths et Angels Santa », Studi Francesi [En ligne], 157 (LIII | I) | 2009, mis en ligne le 30 novembre 2015, consulté le 11 janvier 2021. URL : http://journals.openedition.org/ studifrancesi/8286 ; DOI : https://doi.org/10.4000/studifrancesi.8286

Ce document a été généré automatiquement le 11 janvier 2021.

\section{cc)}

Studi Francesi è distribuita con Licenza Creative Commons Attribuzione - Non commerciale - Non opere derivate 4.0 Internazionale. 
Lieux magiques. Magie des lieux, Mélanges offerts à Claude Foucart, études réunies et présentées par Simone Bernard-Griffiths et Angels Santa

\author{
Philippe Andrès
}

\title{
RÉFÉRENCE
}

Lieux magiques. Magie des lieux, Mélanges offerts à Claude Foucart, études réunies et présentées par Simone BERNARD-GRIFFITHS et Angels SANTA, Clermont-Ferrand, Presses Universitaires Blaise Pascal, 2008, «Révolutions et Romantismes», pp. 226.

1 En liminaire de ce court ouvrage, Simone BERNARD-GRIFFITHS retrace la vie académique de Claude Foucart, dédicataire du présent livre qui n'est «qu'une invitation à de nouveaux voyages» (p.7) issus des travaux des Centres de recherche de Lleida et de Clermont-Ferrand. Du paysage sandien à la métamorphose itinérante de la création littéraire en passant par la féerie urbaine, tel est le fil qui dirige le lecteur tout au long de ces Mélanges.

2 Nous nous sommes intéressé plus particulièrement au Livre I («Magie des paysages», pp. 11-73) que Pascale AURAIX-JoNCHiÈRE introduit par son étude sur George Sand et la magie des neiges (pp.11-21). L'hiver à la campagne occupe une place symbolique d'importance dans l'œuvre de Sand, notamment dans Histoire de ma vie. Bon nombre de récits sandiens voient fleurir ce thème comme autant $d^{\prime}$ '«impressions» qui touchent «à la description proprement dite qu'à la perception des personnages ou à la nature du récit» (p. 12). Ainsi le paysage se transforme-t-il en lieu de sublimation amoureuse dans Indiana et la neige vient-elle ouvrir un espace intérieur qui prendra une place de plus 
en plus grande dans l'univers romanesque de George Sand. La blancheur et le silence de la neige jettent un pont entre vie consciente et inconsciente en une véritable «transfiguration poétique du réel» (p. 18). Avec la glace, la neige forme une polarisation particulièrement onirique en développant un véritable «imaginaire polaire» comme dans le récit de Laura.

Simone BERNARD-GRIFITHS, quant à elle, dans Magies volcaniques en pays d'Auvergne: "L'Orgue du Titan" (1873) de George Sand entre récit de voyage, conte et mythe (pp. 23-40), s'intéresse avec acuité au deuxième récit des Contes d'une grand-mère et à sa "complexité générique» (p.23). Le titre, dans sa genèse même, constitue une véritable énigme puisque le substantif «orgue» peut s'entendre aussi bien dans un sens musical que géologique. L'Auvergne peut se comprendre à la fois comme un lieu référentiel à l'intérieur duquel le voyage vécu joue un rôle déterminant, mais aussi comme un espace onirique et mythique invitant le lecteur à une véritable «initiation géologique» (p.27) et le voyage alors devient une «révélation cosmogonique» (p.32) dans un univers qui demeure toutefois inquiétant. En jouant sur l'onomastique (Chanturgue/ Chante-orgue; Sanadoire/Sonatoire) S. Bernard-Griffiths circonscrit le mystère de Chanturgue dans sa «prégnance symbolique» (p.34) et le langage joue littéralement avec le domaine féerique. Maître Jean se mue ainsi en Titan malheureux et Angelin, quant à lui, réussit intégralement sa métamorphose en artiste-titan. Le récit sandien obéit donc à une double postulation - celle de la nature et celle du merveilleux - et tend à construire une image archétypale de l'artiste romantique.

4 Pour sa part, Élise RADIX, dans Magies romantiques $d u$ rocher, entre recueillement mélancolique et révolte titanesque (pp. 41-54), analyse le rôle de «la thématique naturiste dans le mouvement préromantique» (p.41) et, plus particulièrement, le motif du rocher, qui s'inscrit, au début du XIXe siècle, dans un imaginaire ouvert par les poèmes d'Ossian, dans un contexte épique magnifiant les vertus héroïques, entre mélancolie et action. Le rocher devient le symbole de l'homme individuel dans son rapport à la société, mais aussi de sa recherche d'absolu dans une quête d'allure prométhéenne, en plein romantisme.

5 Cet ouvrage de facture agréable nous invite à reprendre les perspectives d'une critique thématique cernant l'imaginaire individuel et collectif d'auteurs qui ont, pour la plupart, perçu leur monde de façon «magique». 